\title{
Applications of a Ground-source Heat Pump System with Complementary Functions in Different Areas
}

\author{
YuxuanShang ${ }^{1, a}$ andYuefen Gao ${ }^{1, b}$ \\ ${ }^{1}$ School of Energy Power and Mechanical Engineering, North China Electric Power University, \\ Baoding071003,China. \\ ashangyuxuan1996@163.com, bgaoyuefen@163.com
}

Keywords: Ground-source heatpump, soil thermal imbalance, operationcontrol strategies.

\begin{abstract}
According to the problem of the soil thermal imbalance occurring in the ground-source heat pump system, a new kind of ground-source heat pump system with complementary functions is established. This system can be applied in different climate areas through rational controlling strategies. In the study, a cooling tower and a solar collector are added to compensate energy. By analyzing the annual loads, different operation control strategies are put forward for four cities from different typical climate zones in China. The compensation measures introduced into the system ensure the system to operate more effectively and more flexibly.
\end{abstract}

\section{Introduction}

Ground source heat pump system is widely used in the world. In the last decades, China has been setting up this kind of system in many cities. However, some problems occurred after a long-term operation. Among the problems, the soil thermal imbalance is almost the most prominent. Some researchers have carried out studying on the problem and proposed some measures. [1-5] Wang Huajun and Zhao Jun put forward a kind of system with the ground source heat pump and the cooling tower. They found that using the cooling tower could decrease the soil thermal imbalance effectively and recommend an operating mode by setting the average water temperature of buried pipes.[4]But these measures only can be used in the specific conditions or regions. Thus, a new kind of ground source heat pump system with complementary functions is proposed and studied.

\section{Design of the Ground Source Heat Pump System with Complementary Functions}

The system mainly consists of a ground-source heat pump, a cooling tower, a solar collector and other auxiliary equipment and components. It can operate at various conditions and at any time through controlling a set of valves.

In the system, the ground-source heat pumpsand underground pipes are the main parts, while thecooling towers and the solar collectors are the auxiliaryparts. Various equipment runindividually or jointly through controlling thevalves. Specifically, it includes a ground-source heat pump unit, underground pipes, a cooling tower, a solar collector, three circulating pumps, valves,ceiling radiant panels, a fresh air unit,pipes, and so on (see Fig. 1).

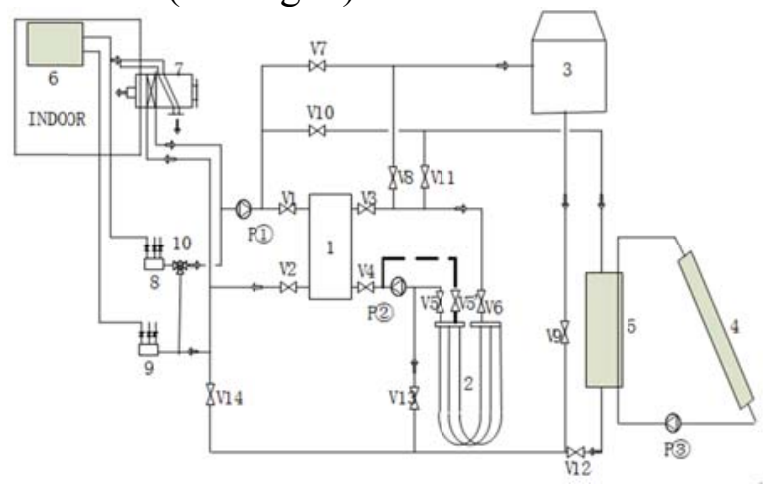

Fig.1 Ground-source heat pump system with complementary functions 
According to the figures of the all-year hourly air condition load per unit area, the year is divided into the winter heating period and the summer cooling period and the transition season on the basis of the load more than or less than $50 \mathrm{~W} / \mathrm{m}^{2}$ lasting for $5 \mathrm{~h}$. Then the appropriate base load is assumed, and the base load should lie on the middle of the hourly load point as possibly. $q_{d l}$ is assumed the winter base load and $q_{x l}$ is the summer base load. The total heating load $Q_{d l}$ is equal to the sum of the winter load smaller than $q_{d 1}$. The total cooling load $Q_{x l}$ is equal to the sum of the summer load smaller than $q_{x 1}$.

The relation of the total winter load in the buried pipe side and the user side can be shown as equation (1).

$$
Q_{d 2}=Q_{d 1}\left(1-\frac{1}{C O P_{d}}\right)(1)
$$

where $Q_{d 2}$ is the buried pipe side total heating load and $C O P_{d}$ is the coefficient of performance for heating.

The relation of the total summer load in the buried pipe side and the user side can be shownas equation (2).

$$
Q_{x 2}=Q_{x 1}\left(1+\frac{1}{C O P_{x}}\right)(2)
$$

where $Q_{x_{2}}$ is the buried pipe side total cooling load and $C O P_{x}$ is the coefficient of performance for cooling.

The relation of the length of the pipe for winter and the base heating load can be shown as equation (3).

$$
L_{d}=\frac{q_{d 1} S}{30}(3
$$

where $L_{d}$ is the length of the pipe for winter and $S$ is the total construction area.

The relation of the length of the pipe for summer and the base cooling load can be shown as equation (4).

$$
L_{x}=\frac{q_{x 1} S}{30}(4)
$$

where $L_{x}$ is the length of the pipe for summer.

The larger one of $L_{d}$ and $L_{x}$ is the length of buried pipe. And it is used to determine the numbers of the borehole because the long pipes are put into the boreholes in the double-U style.

The relation between the capacity of the cooling tower and the remaining summer peak load can be shown as equation (5).

$$
\phi_{l}=q_{x 2} S(5)
$$

where $\Phi_{l}$ is the capacity of the cooling tower and $q_{x 2}$ is the remaining summer peak load.

The relation between the capacity of the solar collector and the remaining winter peak load can be shown as equation (6).

where $\Phi_{t}$ is the capacity of the solar collector and $q_{d 2}$ is the remaining winter peak load.

$$
\phi_{t}=q_{d 2} S(6)
$$

In transition seasons, we need cooling towers to compensate for cold or solar collectors to compensate for heat in order to eliminate the thermalimbalance inthe ground.

When the cooling tower compensates, the relation among the capacity of the cooling tower, the total construction area and the compensating days can be shown as equation (7).

$$
\phi_{l}^{\prime}=\frac{Q_{1} S}{24 d}(7)
$$

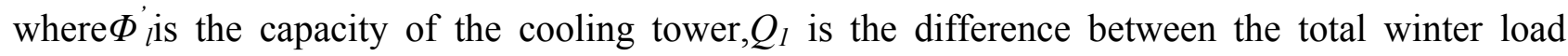
$Q_{d 2}$ and the total summer load $Q_{x 2}$ in the buried pipe side, dis the compensating days.

When the solar collector compensates, the relation among the capacity of the solar collector, the total construction area and the compensating days can be shown as equation (8). 


$$
\phi_{t}^{\prime}=\frac{Q_{1} S}{24 d}(8)
$$

where $\Phi_{t}^{\prime}$ is the capacity of the solar collector.

Thelarger one of $\Phi_{l}$ and $\Phi_{l}^{\prime}$ is the capacity of the cooling tower. Likely, the larger one of $\Phi_{t}$ and $\Phi_{t}^{\prime}$ is used as the capacity of the solar collector. Based on the data, the cooling tower and the solar collector can be chosen. Then, the heat pump unit, the circulating pumps, and the control valves can also be chosen.

\section{Operating Strategies}

The system can operate in the following modes.

The Ground-source Heat Pump and the Underground Pipe CoolingOnly.This mode is suitable for the areas that the soil temperature field is in balance all year. The system provides the cooling load for the users. Under this condition, the valves V1, V2, V3, V4, V5, V6, the circulating pump p(1),p(2) are open, while the valves V7, V8, V9,V10, V11, V12, V13, V14, V5' are closed.

The Ground-source Heat Pump, the Underground Pipe and the Closed Cooling Tower Cooling Together. This mode is suitable for the areas that the heat stacks occur. In the system, the underground pipe and the cooling tower release the heat to the ground and the air. The system provides the cooling load for the users.In this mode, the valves V1, V2, V3, V4, V5, V6, V8, V9, V13and the circulating pump $\mathrm{p}(1)$, $\mathrm{p}$ (2) are open, while the valves V7, V10, V11, V12, V14, V5' are closed.

The Closed Cooling Tower and the Underground Pipe Working Together. This mode is used in transient season. If the soil temperature rises up, the closed cooling tower cools down the water and sends it to the ground to balance the soil temperature deviation. In this mode, the valves V5', V6, V8, V9, V13and the circulating pump p(2) are open, and the valves V1, V2, V3, V4, V5, V7, V10, V11, V12, V14 are closed.

The Heat Pump and the Solar Collector Supplying HeatOnly. This mode is suitable for the situation that the heating load is relatively small, and the temperature of water from the tank is not high enough for users at the preliminary heating time and the end heating time. Under this condition, the valves V1, V2, V3, V4, V11, V12, V13 and the circulating water pump p(1),p(2), p(3) are open, and the valves V5, V6, V7, V8, V9, V10, V14, V5' are closed.

The Ground-source Heat Pump, the Underground Pipe and the Solar Collector SupplyingHeatTogether.This mode is suitable for most of the heating term. In this mode, the valves V1, V2, V3, V4, V5, V6, V11, V12, V13 and the circulating pump p(1), $\mathrm{p}$ (2) are open, while the valves V7, V8, V9, V10, V14, V5' are closed.

The Underground Pipe and the Solar Collector Working Together. Similarly to section 1.3, if the soil temperature decreases, the solar collector heats the water and sends it to the ground to balance the soil temperature deviation. In this mode, the valves V5', V6, V11, V12, V13and the circulating pump $\mathrm{p}^{2}$, $\mathrm{p}_{\text {(3) }}$ are open, and the valves V1, V2, V3, V4, V5, V7, V8, V9, V10, V14 are closed.

\section{Case Study}

Fig. 2 shows the annual loads of Beijing, Shanghai, Harbin, and Guangzhou, respectively. According to the load distribution in different areas, the summer cooling time, the winter heating time and the transition seasons are determined. At different stages, the system operates in different modes to supply heating or cooling for users, or to compensate the thermal imbalance.

Fig. 2(a) shows that the summer cooling load is equal to the winter heating load in Beijing roughly. The winter heating period is regarded from November 5 to March 25, the summer cooling period is from June 15 to September 1, and the other time is the transition period. The winter base load is $60 \mathrm{~W} / \mathrm{m}^{2}$, and the summer base load is $100 \mathrm{~W} / \mathrm{m}^{2}$. Fig. 2(b) shows that the summer cooling load is equal to the winter heating load in Shanghai roughly. The winter heating period is regarded from December 6 to March 22, while the summer cooling period is fromMay 31 to September 
26 , and the other time as the transition season. The winter base load is $60 \mathrm{~W} / \mathrm{m}^{2}$, and the summer base load is $100 \mathrm{~W} / \mathrm{m}^{2}$. Fig. 2(c) shows that the heating load of Harbin in winter is significantly greater than the cooling load in summer. The winter heating period lasts very long from October 15 to April 3, while the summer cooling period is from July 7 to August 16, and the other time is the transition season. The winter base load is $100 \mathrm{~W} / \mathrm{m}^{2}$, and the summer base load is $50 \mathrm{~W} / \mathrm{m}^{2}$.Oppositely, the heating load in winterof Guangzhou is significantly less than the cooling load in summer (see Fig. 2(d)). The winter heating period is regarded from December 1 to February 5, while the summer cooling period is fromApril 29 to October 19, and the other time as the transition season. The winter base load is $40 \mathrm{~W} / \mathrm{m}^{2}$, and the summer base load is $110 \mathrm{~W} / \mathrm{m}^{2}$.

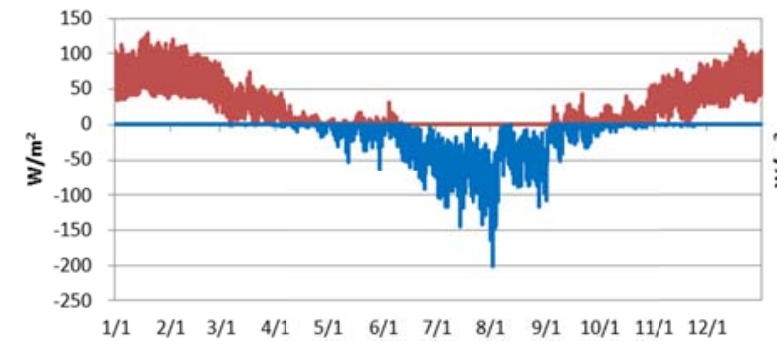

(a) Beijing

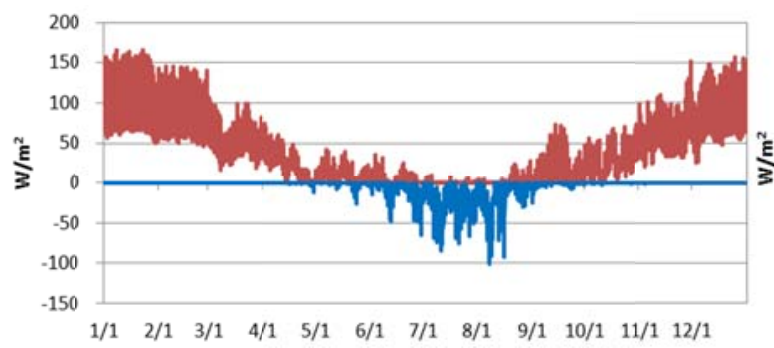

(c) Harbin

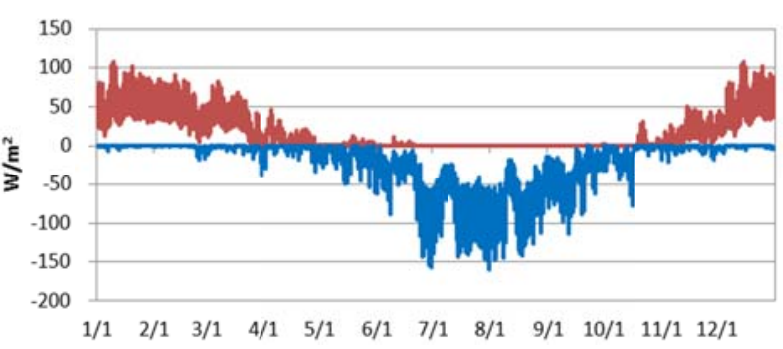

(b) Shanghai

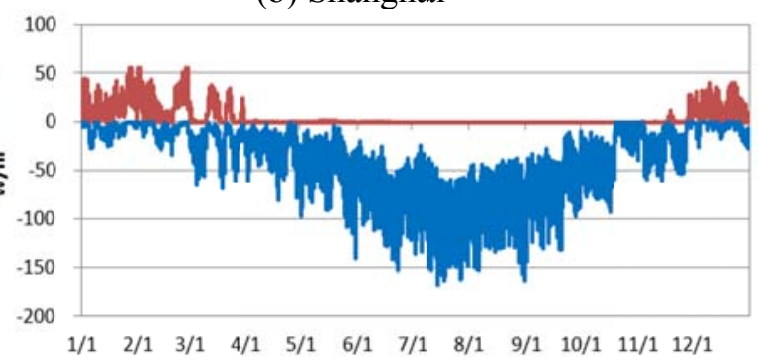

(d) Guangzhou

Fig.2All-year hourly air condition load per unit area in different cities

Based on the fundamental data, the design calculations of the four typical cities are carried out. Table 1 shows the results of the four cities.

Table 1Calculation data of the four typical cities

\begin{tabular}{|c|c|c|c|c|c|c|c|c|}
\hline & \multicolumn{2}{|c|}{ Beijing } & \multicolumn{2}{|c|}{ Shanghai } & \multicolumn{2}{|c|}{ Harbin } & \multicolumn{2}{|c|}{ Guangzhou } \\
\hline & summer & winter & summer & winter & summer & winter & summer & winter \\
\hline Total load,kW/m² & 125 & 117 & 192 & 134 & 33 & 223 & 287 & 21 \\
\hline $\begin{array}{c}\text { Load } \\
\text { difference, } \mathrm{kW} / \mathrm{m}^{2}\end{array}$ & \multicolumn{2}{|c|}{8} & \multicolumn{2}{|c|}{58} & \multicolumn{2}{|c|}{-190} & \multicolumn{2}{|c|}{266} \\
\hline Pipe length, $\mathrm{m}$ & \multicolumn{2}{|c|}{1342} & \multicolumn{2}{|c|}{1342} & \multicolumn{2}{|c|}{1342} & \multicolumn{2}{|c|}{1474} \\
\hline Borehole number & \multicolumn{2}{|c|}{4} & \multicolumn{2}{|c|}{4} & \multicolumn{2}{|c|}{4} & \multicolumn{2}{|c|}{4} \\
\hline $\begin{array}{l}\text { Cooling tower } \\
\text { capacity, kW }\end{array}$ & \multicolumn{2}{|c|}{40} & \multicolumn{2}{|c|}{26} & \multicolumn{2}{|c|}{20} & \multicolumn{2}{|c|}{36} \\
\hline $\begin{array}{l}\text { Solar collector area, } \\
\mathrm{m}^{2}\end{array}$ & \multicolumn{2}{|c|}{5.463} & \multicolumn{2}{|c|}{3.013} & \multicolumn{2}{|c|}{17.56} & \multicolumn{2}{|c|}{2.272} \\
\hline
\end{tabular}

For Beijing, because the cooling load is more than heating load, the cooling tower is used to compensate for the soil thermal imbalance.Theunderground pipe and the cooling tower cooperate from June 15 to September 1 as the summer cooling period. At this period, the underground pipe runs entirely with a constant capacity and the capacity of the cooling tower is adjustable according to the remaining peak load on the user side. The period from September 2 to November 4 is the compensating time of the transition season.Thecapacity of the underground pipe is adjustable according to the load on the user side and the capacity of the cooling tower is constant by $40 \mathrm{~kW}$ to compensate for soil. Thewinter heating period is from November 5 to March 25, and theunderground pipe and the solar collector cooperate. Theunderground pipe runs partly with a constant capacity and the capacity of the solar collector is adjustable according to the remaining peak load on the user side. 
For Shanghai, the cooling tower is also used to compensate for soil, as the cooling load is more than the heating load.Theunderground pipe and the cooling tower cooperate fromMay 31 to September 26 as the summer cooling period. At this period,the underground pipe run entirely with a constant capacity and the capacity of the cooling tower is adjustable according to the remaining peak load on the user side. The period fromSeptember 27 to December 5 is the compensating time of the transition season. The capacity of the underground pipe is adjustable according to the load on the user side and the capacity of the cooling tower is constant by $26 \mathrm{~kW}$ to compensate for the soil temperature. The winter heating period is from December 6 to March 25, and the underground pipe and the solar collector cooperate. The underground pipe runs partly with a constant capacity and the capacity of the solar collector is adjustable according to the remaining peak load on the user side.

As for Harbin, the annual heating load in winter is significantly greater than the cooling load insummer; the solar collector is used to compensate for the soil thermal imbalance.Theunderground pipe and the cooling tower cooperate from July 7 to August 16 as the summer cooling period. The underground pipe run entirely with a constant capacity and the capacity of the cooling tower is adjustable according to the remaining peak load on the user side. The underground pipe and the solar collector cooperate from October 15 to April 3 as the winter heating period the underground pipe runs partly with a constant capacity and the capacity of the solar collector is adjustable according to the remaining peak load on the user side. During the period of April 4 to July 6 and August 17 to October 14, the capacity of the underground pipe is adjustable according to the load on the user side and the capacity of the solar collector is constant by $27 \mathrm{~kW}$ to compensate for soil thermal balance.

For Guangzhou, the cooling loads in summer is greatly more than the heat loads in winter, thecooling tower is needed to compensate for the soil thermal imbalance.The underground pipe and the cooling tower cooperate fromApril 29 to October 19 as the summer cooling period. Atthis period, the underground pipe runs entirely with a constant capacity and the capacity of the cooling tower is adjustable according to the remaining peak load on the user side. During the winter heating period fromNovember 30 to February 5, the underground pipe and the solar collector cooperate. The underground pipe run partly with a constant capacity and the capacity of the solar collector is adjustable according to the remaining peak load on the user side.

\section{Summary}

According to the different load conditions of the cities, the ground-source heat pump system with compensation functions is put forward. The system can operate in different control strategies. It can not only ensure the needs of the users, but also solve the problems of the soil thermal imbalance effectively. This is benefit to the ground-source heat pump wider application.

\section{Acknowledgement}

This study is supported by the foundation of the National College Students' Innovative Entrepreneurial Training Projects and by the Natural Science Foundation ofHebei Province in 2014 (E2014502123).

\section{References}

[1] A.M. Omer, Ground source heat pump systems and applications, Renewable and Sustainable Energy Reviews, 2008, 12(2)1364-0321.

[2] M. Millan, Jim, Ground source heat pumps in schools, ASHRAE Journal, 2007, 49(9) 0001-2491.

[3] W.L. Qiao, J.F. Chen, A study on hybrid ground source heat pump control strategy, Building Energy \& Environment, 2015, 4, 1003-0344. 
[4] H.J. Wang, J. Zhao, Operating control modes of a hybrid ground-source heat pump, HV\&AC,2007,37(9)1002-8501.

[5] Y.Y. Tang, C.G. Jian, X.L. Zhang, X.F. Zhu, The design and economic analysis of ground source heat pump, China science paper online, 2009,2095-2783. 